\title{
DESEMPENHO DE AVESTRUZES NA FASE INICIAL DE CRESCIMENTO, ALIMENTADOS COM DIETAS SUPLEMENTADASCOMCONCENTRADO DE LEVEDURAS VIVAS
}

\author{
Ostriches Performance in the Initial Phase of Growth Feed With \\ Diets With Live Yeasts Concentrate Supplementation
}

\author{
Joana D'Arc Silveira Souza ${ }^{1}$ \\ Walter Motta Ferreira ${ }^{2}$ \\ Dalton de Oliveira Fontes ${ }^{3}$ \\ Alfredo Navarro 4 \\ Luiz Carlos Machado ${ }^{5}$
}

\section{Resumo}

Foi realizado um experimento com o objetivo de testar os efeitos do concentrado de leveduras vivas para avestruzes na fase inicial de crescimento, de 7 a 84 dias. Foram selecionados, ainda no incubatório, 36 filhotes, dos quais foram divididos em dois grupos de 18 animais cada. Os tratamentos consistiram de uma dieta com e sem adição de concentrado de leveduras vivas. Foram realizados os procedimentos de rotina dos primeiros dias, bem como pesagem inicial. O delineamento experimental foi inteiramente casualizado com dois tratamentos e 18 repetições, sendo cada animal uma unidade experimental. Para avaliação do ganho de peso semanal, os animais foram pesados ao final de cada semana. Houve diferença significativa $(\mathrm{P}<0,05)$ para 0 ganho de peso aos 28 dias de idade. Foi observado um melhor desempenho do tratamento levedura no período de maior estresse, que coincidiu com o ensaio de digestibilidade onde os filhotes ficaram alojados em baias com movimentos restritos, do $73^{\circ}$ ao $84^{\circ}$ dia do experimento. 0 concentrado de leveduras vivas influenciou o ganho de peso na quarta semana de vida dos filhotes de avestruz em crescimento.

Palavras-chave: Desempenho, Avestruz, Leveduras vivas, Probiótico.

\section{Abstract}

An experiment was accomplished with the objective of testing the effects of the live yeasts concentrate for ostriches in the initial phase of growth, from 7 to 84 days. They were selected, still in the incubator, 36 nestlings, divided in two groups of 18 animals each. The treatments consisted of a diet with and without addition live yeasts concentrate. The procedures of routine of the first days were accomplished, as well as initial weighting. The experimental design was entirely randomized with two treatments and 18 replications, being each animal an experimental unit. For eamings evaluation, the animals were weighted at the end of the week. There was significant difference $(P \varangle 0,05)$ for the weight earnings in the 28 days of age. A better performance of the treatment yeast was observed in the larger stress period, that it coincided with the essay of digestibility, where the nestlings were housed in stalls with restricted movements, of the 73 to the 84th day of the experiment. The live yeasts concentrate influenced the weight earnings in the fourth week of life of the ostrich nestlings in growth.

Keywords: Performance, Ostrich, Live yeasts, Pro-microbials.

1 Doutoranda em Ciência Animal. Departamento de Zootecnia, Escola de Veterinária, UFMG. Caixa Postal 567. CEP 30123-970. Belo Horizonte. Minas Gerais. E-mail: joanadarc-1@hotmail.com, parte da dissertação de mestrado.

Professor Adjunto, EV/UFMG, Orientador.

3 Professor Adjunto, EV/UFMG, Colaborador.

4 Colaborador, Gerente Geral da SAF do Brasil, Colaborador.

5 Doutorando, EV/UFMG, Colaborador. 


\section{Introdução}

Após dez anos do início da estrutiocultura no Brasil, as perspectivas para essa criação são as melhores, apesar de toda a instabilidade econômica que o país vem experimentando, cada vez mais os criadores vêm se especializando em diversos setores.

A nutrição e alimentação dessas espécies são uma incógnita, uma vez que a carência de pesquisas com essas aves faz com que haja uma extrapolação para a formulação das dietas, baseando-se na nutrição de outras espécies. Isto resulta em erros de formulação, causando grandes perdas na produção, principalmente, de filhotes, pois estes são sensíveis às mínimas alterações em sua dieta.

Os conhecimentos relativos às exigências nutricionais dos avestruzes são limitados. No entanto, algumas diretrizes foram estabelecidas por pesquisadores da África e Austrália (SOUZA, 2004).

O uso de probióticos está sendo amplamente estudado e sua utilização é altamente recomendada e não apresenta efeitos colaterais para qualquer espécie animal. Isto se torna mais importante na nutrição dos filhotes de avestruz, pois nascem com o sistema digestório praticamente estéril e sua colonização se dará pela alimentação ou pelo ato de coprofagia.

Com este propósito, assim que o filhote nasce, ele recebe um probiótico à base de microorganismos, durante os três primeiros dias de vida. No entanto, os filhotes com baixa resistência ficam facilmente doentes com qualquer desafio do qual são submetidos quando transferidos do berçário para o setor de cria, aos quatro dias de idade. Um manejo, no qual os filhotes adquiram alta imunidade nesta fase, é necessário e pode ser conseguido por um programa de manejo de administração diária de probiótico.

Alguns autores recomendam a não alimentação dos filhotes na primeira semana de vida. Carbajo (1995) afirma que os filhotes que ingerem alimentos desde os primeiros dias de vida têm dificuldades de absorver o saco vitelino; e quando este não é reabsorvido em sua totalidade, seus restos podem ser facilmente colonizados por diversos patógenos. Por outro lado, Huchzermeyer (2000) recomenda a alimentação dos filhotes a partir do primeiro dia de vida, afirmando que suspender a alimentação com o objetivo de aumentar a velo- cidade de reabsorção do saco da gema pode levar à subnutrição, entre outros problemas.

Giannoni (2002) ainda salienta que os filhotes devem ter livre acesso ao alimento durante as três primeiras semanas de vida e a ração deve ser suplementada com acesso à pastagem (gramínea), o que auxilia no treinamento de pastejo dos filhotes e ainda promove uma função intestinal sadia.

Os filhotes nascidos e criados artificial e intensivamente não têm a oportunidade de entrar em contato com as bactérias necessárias para 0 funcionamento normal do seu sistema digestório, o que não acontece em filhotes criados na natureza. A incapacidade de estabelecer uma flora intestinal normal ou a sua destruição torna a ave susceptível à entrada de patógenos que causam enterite, como as salmonelas e outras enterobactérias (HUCHZERMEYER, 2000).

A busca por uma alimentação saudável aumenta a procura por alimentos alternativos e hoje a concepção de nutracêuticos (alimentos funcionais) está sendo muito utilizada para a criação animal, proporcionando uma melhor saúde do rebanho como um todo. O probiótico é um alimento funcional porque aumenta a imunidade dos animais e, em conseqüência, uma melhoria das condições de sanidade do rebanho.

A Saccharomyces cerevisiae é uma levedura de ampla utilização na indústria de cervejaria e no setor de panificação. É, também, amplamente utilizada em suplementos para a nutrição animal. Segundo Heugten et al. (2003), a suplementação da alimentação animal com leveduras tem a função de estimular a digestão e auxiliar a manutenção do equilíbrio microbiano do trato gastrintestinal de filhotes de suínos.

Esse estudo foi conduzido com o objetivo de avaliar a influência do concentrado de leveduras vivas sobre o ganho de peso de filhotes de avestruz na fase inicial de crescimento.

\section{Material e Métodos}

O experimento foi conduzido na fazenda Aveluz, zona rural do município de Luz, com temperaturas anuais máximas e mínimas de 29,1 e $16,7^{\circ} \mathrm{C}$, respectivamente; e um índice pluviométrico médio anual de 1.415,7 mm (CADBrasil, 2005). 
Os animais foram selecionados, ainda no incubatório, 36 filhotes, e foram aleatoriamente distribuídos em dois grupos: tratamento controle (TC) e tratamento levedura (TL). Nos primeiros dias de vida foram adotados os procedimentos de cura do umbigo, fornecimento de três gramas de probiótico em pasta, além da marcação e pesagem dos filhotes no primeiro dia de vida.

Os filhotes foram transferidos do nascedouro para o berçário (dentro do incubatório) no primeiro dia de vida, após a secagem das penugens no nascedouro, sendo separados em dois grupos por grades. Manteve-se a temperatura ambiente em $33^{\circ} \mathrm{C}$, em média, sendo disponibilizadas ração inicial e água a partir do segundo dia de vida.
Para o TL foi adicionado à ração inicial cinco g/animal/dia de concentrado de leveduras vivas termoestáveis (BIOSAF, Saf do Brasil), contendo mais de $10 \times 10^{9} \mathrm{UFC} / \mathrm{g}$. Pesou-se 90 gramas do concentrado, sendo esse misturado à primeira porção de ração fornecida diariamente. Aos quatro dias de idade foram transferidos para a maternidade (setor de cria), sendo aquecidos durante a noite e soltos no piquete externo durante o dia.

$O$ valor dos nutrientes da ração fornecida pode ser visualizado na tabela 01 . A ração foi oferecida ad libitum, em várias porções durante 0 dia, e ao entardecer as sobras eram pesadas e anotadas. Como volumoso, foi oferecida couve picada. Durante o período experimental, os filhotes tiveram livre acesso à água limpa.

\section{TABELA 1 - Níveis dos princípios nutritivos analisados (base matéria natural) da ração comercial oferecida aos filhotes durante o período experimental.}

Table 1 - Levels of the analyzed nutritional principles (natural base substance) of the offered commercial ration to the nestlings during the experimental period.

\begin{tabular}{|l|r|}
\hline Nutrientes analisados & \\
\hline Energia Bruta (Kcal/kg) & $4.270,09$ \\
Proteína Bruta (\%) & 21,67 \\
Fibra em Detergente Neutro (\%) & 30,20 \\
Extrato Etéreo (\%) & 3,88 \\
Matéria Mineral (\%) & 10,64 \\
Matéria Seca (\%) & 89,28 \\
\hline
\end{tabular}

Foram registradas pesagens semanais dos filhotes com o auxílio de balança eletrônica com precisão de dez gramas. Após 60 dias, os animais foram mantidos no respectivo piquete externo, não sendo recolhidos ao anoitecer, pois nesta fase os filhotes já possuem uma maior resistência.

Os dados foram processados e analisados na Unidade de Processamento de Dados do Departamento de Zootecnia da Escola de Veterinária (UFMG). O procedimento adotado foi o GLM do pacote estatístico SAS (Statistical Analysis System, 1995). O delineamento experimental foi inteiramente casualizado com dois tratamentos (TC e TL) e 18 repetições. 0 ganho de peso aos 84 dias (GP84) foi submetido à análise de variância de acordo com o teste F, com significância de 5\%.

\section{Resultados e Discussão}

\section{Consumo e conversão alimentar}

As médias de ração consumida ( $\mathrm{g} /$ dia) foram de 108, 324 e $648 \mathrm{~g}$ para o TC e 112, 343 e $686 \mathrm{~g}$ para o TL, nos meses um, dois e três, respectivamente; e pode ser visualizado na Figura 01. 


\section{FIGURA 1 - Consumo de ração (valor fornecido subtraído das sobras) durante o período experi- mental}

Figure 1 - Ration consumption (supplied value deducted from the leftovers) during the experimental period

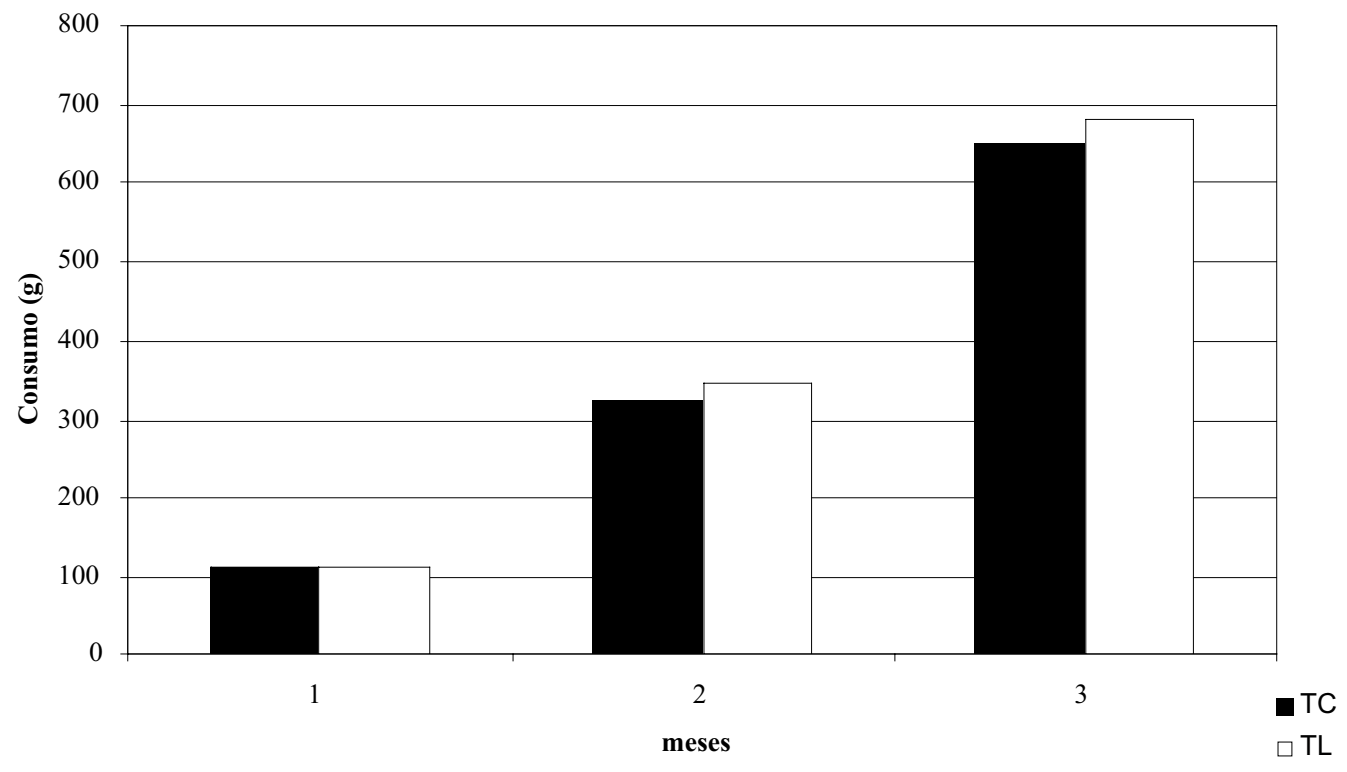

Esses resultados estão de acordo com que sugerem uma média de consumo diário de rações completas para filhotes de zero a um, de um a dois e de dois a três meses, variando de 120; 300 e $500 \mathrm{~g}$ de ração por dia, respectivamente. Contudo, no terceiro mês, o valor encontrado foi superior ao que os autores acima recomendam.
A tabela 02 contém os valores médios de MS consumido (valor fornecido subtraído das sobras). Estes dados são referentes às médias dos grupos alojados ao final do período experimental, do $80 .^{\circ}$ ao $84 . .^{\circ}$ dia.

TABELA 2 - Matéria seca consumida (valor fornecido subtraído das sobras) ao final dos três meses de idade.

Table 2 - Consumed dry matter (supplied value deducted from the leftovers) at the end of the three months of age.

\begin{tabular}{|l|l|}
\hline Tratamento & Consumido \\
\hline TC & 760,22 \\
TL & 741,69 \\
CV (\%) & 20,44 \\
\hline
\end{tabular}

*Não significativo pelo teste $\mathrm{F}(\mathrm{P}>0,05)$ 
Assim como a galinha, o avestruz, não possuindo língua, em sua alimentação há grande desperdício de ração. Mesmo sendo essa fornecida em porções e não tendo desperdício sido avaliado, a melhor estimativa foi obtida a partir dos indicadores observados a campo.

Neste experimento, encontrou-se um va- lor de conversão alimentar de 1,08; 1,32 e 3,23 para o TC e 0,86; 1,49 e 2,63 para o TL, nos meses um, dois e três, respectivamente. Esses dados podem ser graficamente visualizados na Figura 02. Estes valores estão de acordo com Angel (1996), que relata uma conversão alimentar de 1,09 a 2,26 para filhotes machos em crescimento até os 90 dias de idade.

\section{FIGURA 2 - Conversão alimentar durante os três meses de ensaio.}

Figure 2 - Alimentary conversion during the three months of assay.

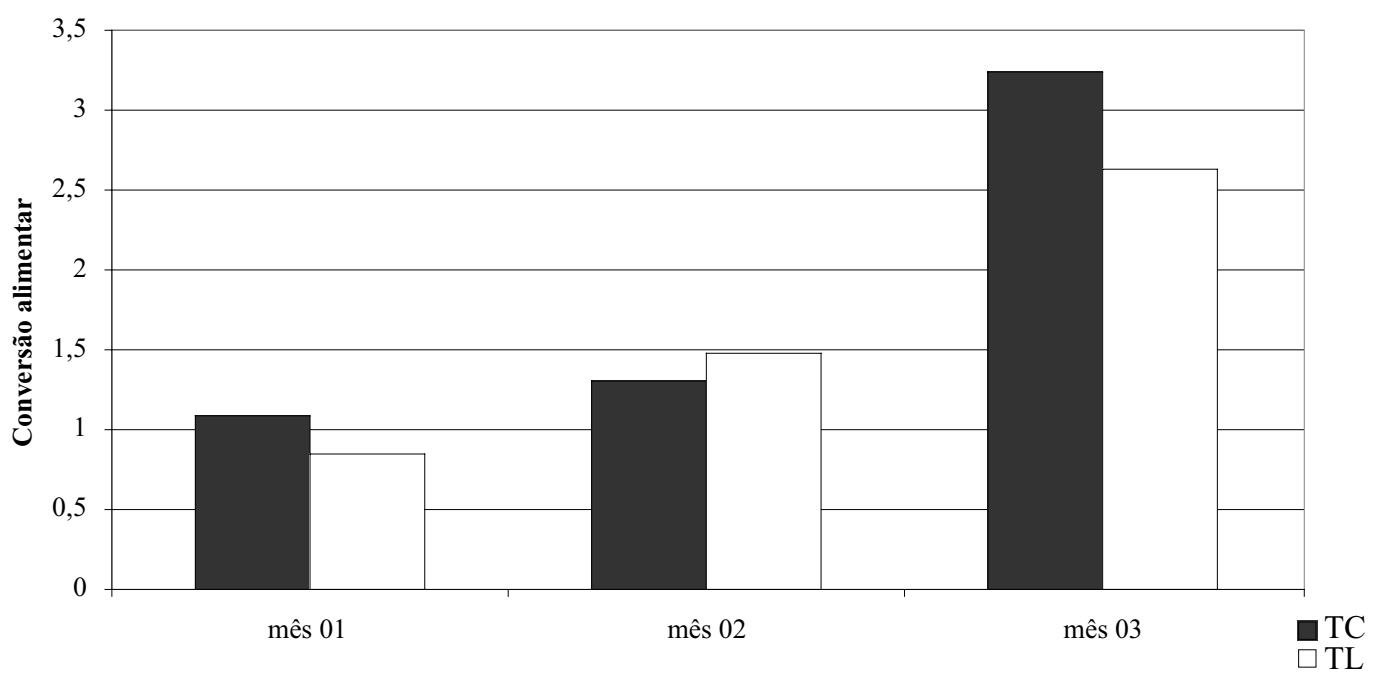

\section{Ganho de peso}

Os dados do ganho de peso final, aos 84 dias, estão descritos na tabela 03 e foram submetidos à análise estatística da qual não houve diferença significativa $(\mathrm{P}>0,05)$ entre os tratamentos.

TABELA 3 - Ganho de peso ( $\mathrm{kg})$ no 84. 0 dia de idade.

Table 3 - Gain of weight $(\mathrm{kg})$ in $84 .$. day of age.

\begin{tabular}{|l|l|}
\hline Tratamento & GP84 \\
\hline TL & 19,481 \\
TC & 17,740 \\
CV (\%) & 25,48 \\
\hline
\end{tabular}

*Não significativo pelo teste $\mathrm{F}(\mathrm{P}>0,05)$ 
As taxas de ganho de peso semanal estão dispostas na tabela 04 . Os valores apresentados pelo tratamento levedura, excetuando-se o 21. $\mathrm{e}$ 56. ${ }^{\circ}$ dia, tiveram uma tendência em melhor ganho de peso em relação ao tratamento controle. Como pode ser visualizado na figura 03 , observou-se um melhor desempenho do tratamento levedura no período de maior estresse, sendo esse o ensaio de digestibilidade onde os filhotes ficaram alojados

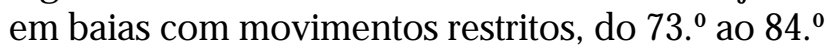
dia do experimento.

\section{TABELA 4 - Ganho de peso semanal (g) dos tratamentos controle e levedura durante o período experimental.}

Table 4 - Gain of weekly weight ( $g$ ) of the control and leavening treatments during the experimental period.

\begin{tabular}{|l|l|l|l|l|l|l|}
\hline Tratamento & GP7 & GP14 & GP21 & GP28 & GP35 & GP42 \\
\hline TL & 10,63 & 521,56 & 732,50 & $1.170,00 \mathrm{a}$ & $1.037,50$ & $1.621,30$ \\
TC & 26,94 & 433,61 & 746,10 & $902,50 \mathrm{~b}$ & 961,40 & $1.312,20$ \\
CV (\%) & 510,41 & 31,5 & 50,40 & 37,07 & 42,9 & 33,94 \\
Tratamento & GP49 & GP56 & GP63 & GP70 & GP77 & GP84 \\
TL & $2.071,9$ & $2.023,1$ & $2.334,4$ & $2.816,3$ & $2.796,3$ & $2.345,6$ \\
TC & $1.945,6$ & $2.201,7$ & $2.318,9$ & $2.666,7$ & $2.421,9$ & $1.802,5$ \\
CV (\%) & 30,87 & 29,42 & 29,46 & 33,62 & 33,60 & 68,03 \\
\hline
\end{tabular}

*Médias seguidas de letras diferentes em uma mesma coluna diferem entre si pelo teste $\mathrm{F}(\mathrm{P}<0,05)$

FIGURA 3 - Ganho de peso semanal durante 0 ensaio experimental.

Figure 3 - Gain of weekly weight during the experimental assay.

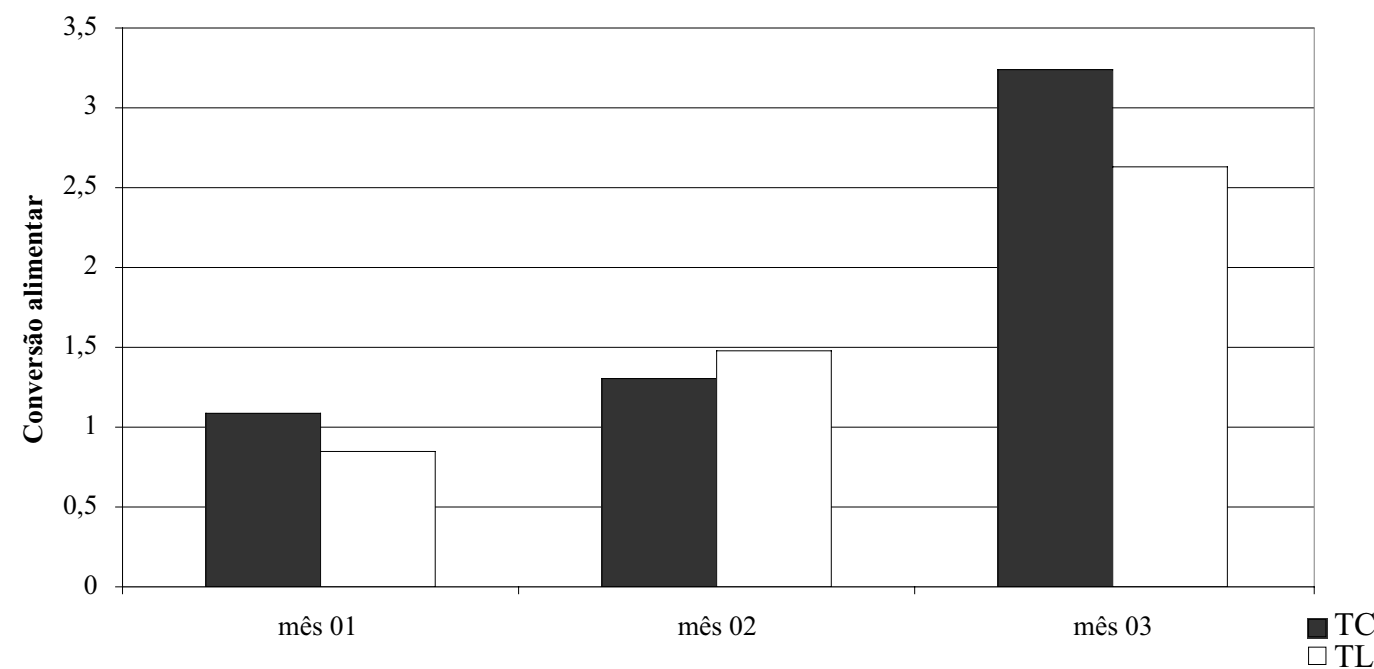


O ganho de peso aos sete dias de idade apresentou um coeficiente de variação muito alto, isto ocorre devido à perda de peso na primeira semana de vida do filhote, uma vez que nascem inchados e com um saco vitelínico muito grande. Contudo, alguns filhotes não apresentam perda de peso nesta fase.

\section{Conclusões}

De acordo com os resultados obtidos, nas condições em que foram realizados os ensaios, podese concluir que o concentrado de levedura viva influenciou significativamente o ganho de peso na quarta semana de idade dos filhotes de avestruz, contudo, mais pesquisas são necessánias, devido aos aspectos inerentes, como a variação genética e variação entre sexos, da espécie em estudo.

\section{Agradecimentos} concedido

A SAF do BRASIL, pelo apoio financeiro

À CAPES, pela concessão da bolsa.

Ao criatório Aveluz e aos associados da ACRIA.COM, pela cessão dos animais e das instalações.

\section{Referências}

CAD Brasil. Disponível em: http:// www.cidadedeluz.com/acidade.php 2005. Acesso em: 10 dez. 2005.

CARBAJO, E. Características anatomicas y fisiológicas: metabolismo, comportamiento. Hematologia. In: CARBAJO, E.; GURRI, A., MESIÀ, J., CASTELLÓ, F. Cria de Avestruces. Espanha: Real Escuela de Avicultura, 1995. Cap. 2, p. 27-47.

GIANNONI, M. L Avestruz, reprodução, cria e recria: Manual CPT. [S. l.: s. n.], 2002. p. 136.

HEUGTEN, E.; FUNDERBURKE, D. W.; DORTON, K. L. Growth performance, nutrient digestibility, and fecal microflora in wealing pigs fed live yeast. Journal of Animal Science, v. 81, p. 1004-1012, 2003.

HUCHZERMEYER, F. W.; Trad. GIANNONI, M. L, NOVAIS, A. A. Doenças de avestruzes e outras ratitas. Jaboticabal: Funep, 2000.

SAS INSTITUTE. SAS user's guide: statistics. Cary: Sas, 1995.

SOUZA, J. D. S. Criação de Avestruz. Viçosa: Aprenda Fácil, 2004. 